\title{
Trend and status of Food Science and Technology category based on the Essential Science Indicators during 2011 - 2021
}

\author{
Bao-Zhong YUAN ${ }^{1 *} \mathbb{D}$, Jie SUN ${ }^{2}$
}

\begin{abstract}
Based on the Essential Science Indicators database, this study analyzed 2,886 top papers in the subject category of Food Science and Technology from January 2011 to June 2021. The 2,886 top papers include 2,882 highly cited papers and 56 hot papers. All papers written in English, were from 10,698 authors, 2,666 organizations and 115 countries/territories, published in 106 journals and two book series in the field. The top five Journals are Food Chemistry, Food Hydrocolloids, Trends in Food Science Technology, Critical Reviews in Food Science and Nutrition and Journal of Agricultural and Food Chemistry. The top six countries and regions were Peoples R China, USA, Spain, Italy, Brazil and India. The top six organizations of Jiangnan University, University of Massachusetts, South China University of Technology, Zhejiang University, Jiangsu University and University of Valencia were popular based on contribution of articles more than 45 papers each. The top five authors were Mcclements David Julian, Sun Da-Wen, Barba Francisco J., Lorenzo Jose M. and Zhang Min. All keywords were separated seven clusters for different research topic. Visualizations offer exploratory information on the current state in a scientific field or discipline as well as indicate possible developments in the future.
\end{abstract}

Keywords: bibliometric analysis; Essential Science Indicators (ESI); Food Science and Technology; top papers; VOSviewer.

Practical Application: Bibliometric analysis of Food Science and Technology.

\section{Introduction}

According to category description for Food Science and Technology in Scope Notes of Science Citation Index Expanded, it covers those resources concerning various aspects of food research and production, including food additives and contaminants, food chemistry and biochemistry, meat science, food microbiology and technology, dairy science, food engineering and processing, cereal science, brewing, and food quality and safety. (Clarivate, 2021b).

Bibliometric analysis is a method assessing the status and trends of a particular research field and thus providing ideas and directions for future research. Bibliometrics technique has been adopted in Web of Science category of Food Science and Technology such as, bibliometric analysis of food safety governance research from 1999 to 2019 (Shen et al., 2021), a knowledge domain visualization review of thirty years of halal food research (Mostafa, 2020), Atlas of scientific institutions in food science (Guerrero-Bote et al., 2016), characteristics and trends in global tea research (Wambu et al., 2017), destination food research (Lyu et al., 2020), exploring the scientific interest for olive oil origin (Maléchaux et al., 2020), Food label design (Latino et al., 2020), Innovation, research and development on the passion fruit peel flour (Florêncio et al., 2020), internet of things in food safety (Bouzembrak et al., 2019), Let food be thy medicine and medicine be thy food (Yeung et al., 2018), mapping the scientific research on wine and health (Aleixandre et al.,
2013), recent developments on production, purification and biological activity of marine peptides (Sridhar et al., 2021), research trends in food chemistry (Kamdem et al., 2019), the berries on the top (Yeung et al., 2019), trends in research on durum wheat and pasta (Cecchini et al., 2020), urban food systems (Zhong et al., 2021).

Top papers are the sum of hot papers and highly cited papers, based on Clarivate Analytics' Essential Science Indicators (ESI). The ESI database is widely used to assess scientific outputs. Highly cited paper is a paper that belongs to the top $1 \%$ of papers in a research field published in a specified year. The $1 \%$ is determined by the highly cited threshold calculated for the research field in the specified year. Hot paper is a paper published in the past two years that received a number of citations in the most recent two-month period that places it in the top $0.1 \%$ of papers in the same field. A bibliometric evaluation of highly cited papers with high-level representation was conducted during the period from 1999 to 2009 based on the Essential Science Indicators (ESI) database (Fu et al., 2011), highly cited papers in the field of Economics and Business based on the Essential Science Indicators database (Zhang et al., 2018), highly cited papers in operations research and management science from 2008 to 2017 (Liao et al., 2019), highly cited papers in environmental sciences (Ma et al., 2020), macro-level collaboration network analysis and visualization with Essential Science Indicators: 
A case of social sciences (Yang et al., 2020), and high-impact papers presented in the subject category of water resources in the Essential Science Indicators database (Chuang et al., 2011). Sun and Yuan have analyzed the top papers in world rice research (Sun \& Yuan, 2020a), Library and Information Science (Sun \& Yuan, 2020b), water Resources (Sun \& Yuan, 2020c), Agronomy category (Sun \& Yuan, 2021), green and sustainable science and technology (Yuan \& Sun, 2019), scientific research on maize or corn (Yuan \& Sun, 2020a, 2020b) and wheat (Yuan \& Sun, 2021).

The purpose of this paper was to use bibliometric methods to analyze top papers in the subject category of Food Science and Technology during 10 years and 6 months period from January, 2010 to June, 2020 through publication year, category, author, affiliations, country, journals, keywords and other key features. Co-authorship network visualization of author, organizations and countries, co-occurrence network visualization of all keywords were done by VOSviewer. Special attention will be dedicated to research topics and research fronts.

\section{Materials and methods}

\subsection{WoS and Essential Science Indicators (ESI)}

Clarivate Analytics's WoS is the world's leading scientific citation search and analytical information platform, and the one of the world's largest and most comprehensive academic information resources covering more than 12,361 core academic journals. The publication counts from the WoS Core Collection were derived from the following databases: The Science Citation Index-Expanded (SCIE)-- 1900-present, Social Science Citation Index (SSCI)--1900-present, Conference Proceeding Citation Index-Science (CPCI-S)--2015-present, Conference Proceedings Citation Index-Social Science \& Humanities (CPCI-SSH) --2015-present, Current Chemical Reactions (CCR-EXPANDED) --1985-present, Index Chemicus (IC) --1993-present.

Essential Science Indicators (ESI) is a unique compilation of performance statistics and trends extrapolated from counts of articles published in scholarly journals and the citations to those articles. ESI is an analytical tool that helps you identify top-performing research in WoS Core Collection. Article counts for ESI are derived from more than 12,000 journals indexed in WoS Core Collection (SCIE and SSCI only) over a 11-year period. Citation counts for these articles are derived from journals indexed in WoS Core Collection (SCIE, SSCI and Arts \& Humanities Citation Index). Each journal is assigned to one of 22 research fields. In ESI a journal can be assigned to only one field. Journals such as Science and Nature are categorized as multidisciplinary since they publish research in many different fields. As a result, papers published in these multidisciplinary journals are assigned to a field based on the representation of the cited journals. For example, if the majority of cited references in the paper are to neuroscience journals, the paper is then categorized as neuroscience (Clarivate, 2021a). Here, the Essential Science Indicators database has been updated as of September 8,2021 , to cover a 10 year and six months period from January 1, 2011 to June 30, 2021. Papers are defined as regular scientific articles and review articles.

\subsection{Data collection}

Data collection was completed on the single day on September 9, 2021 to avoid the bias. We first conducted a advanced search in the WoS category (WC) of Food Science and Technology and publication year (PY) from 2011 to 2021. The query as following: (WC= Food Science and Technology) AND (PY: 2011-2021)

The results were used to identify the top papers of the highly cited papers and hot papers in field. There are 2,886 top papers from WoS Core Collection. Full record and cited references of the included papers were extracted and imported into VOSviewer (Leiden University, Leiden, the Netherlands) for further citation analysis. The impact factors (IF 2020 and IF 5year) were taken from the Journal Citation Report (JCR 2020) published in 2021, which had the latest data available.

\subsection{VOSviewer}

Visualizations (network and overlay) using program VOSviewer are conducted on WoS data in order to determine co-occurrence and clusters of connected publications, country input and author collaboration (co-authorship) as well as clusters of interrelated research topics (text data). In this work, we used VOSviewer to show the international collaboration between the authors, organizations, countries and the research trends through all keywords (Van Eck \& Waltman, 2010). In this paper, default parameters values of the VOSviewer are usually used in the analysis. Items are represented by a label and a circle. The size of circles reflects the weight of an item. Some items are not displayed in avoidance of overlapping. The colors in network visualization (text maps) represent clusters of similar items as calculated by the program. Distance between the items indicates the strength of relationships.

\section{Results and discussion}

\subsection{Document type and language of publication}

Based on Clarivate Analytics's WoS Index, there were total 2,886 top papers of the Food Science and Technology category during the period from January, 2011 to June, 2021. All of 2,886 top papers were identified in SCIE $(2,886)$, SSCI (108), CPCI-S (77), book citation index-Science (31)'and index chemicus (16)!' In the ESI database, papers are defined as regular scientific articles and review articles. The document types of all 2,886 top papers were articles $(1,612,55.856 \%)$, reviews $(1,274$, $44.144 \%)$, proceedings papers $(77,2.668 \%)$, book chapter (31, $1.074 \%)$ and early access (3, $0.104 \%)$.

Among the all 2,886 top papers, there are 56 hot papers and 2,882 the highly cited papers that means 52 papers are both the hot papers and the highly cited papers. All papers were published in English, among that, only one paper also was in Estonian. The English was dominating language from the WoS, and scholars tend to publish their articles in English as they want them to be widely accepted. Moreover, most of the published documents were in the form of original research articles written in English language (Khan et al., 2020). 


\subsection{Publication output}

With the aim of knowing the research status and trend, Figure 1 shows the top paper of Food Science and Technology category between 2011 and 2021. The mean publication was 262.36 each year, and the highest value was 385 in 2020 , though there is a half year of 2021. An increase in the number of cited references indicates that there are more citing or cited publications. The number of citations to a paper is considered a good quantitative measure of a paper's impact. The $h$-index was initially proposed as a measure of a researcher's scientific output based on counting the number of publications $(\mathrm{N})$ by

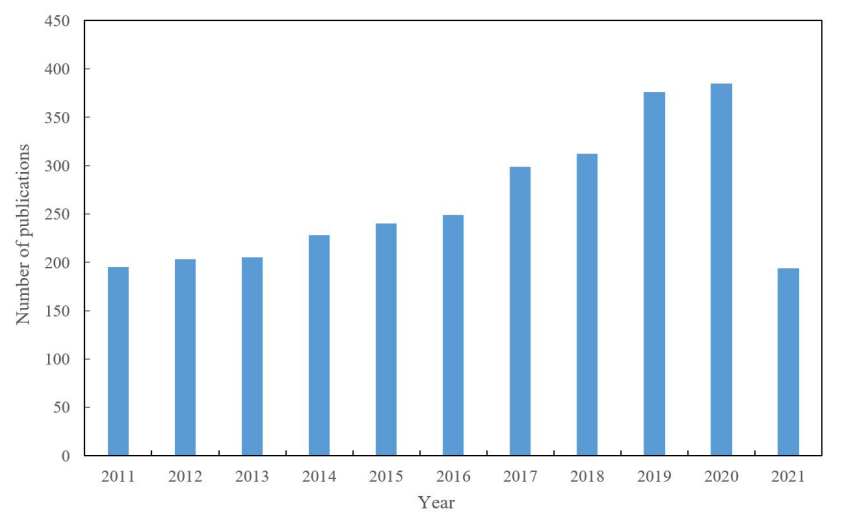

Figure 1. Number of published top papers of Food Science and Technology category per year from January 2011 to June 2021. that researcher cited $\mathrm{N}$ or more times (Hirsch, 2005). For the total 2,886 papers, the $h$-index is 260 , and the average citation per item is 131.3 .

\subsection{Web of Science categories and research areas}

Each paper indexed by the WoS belongs to one or more subject categories. There are total 28 WoS subject categories including Food Science and Technology categories in the science edition (total 254 categories) and 21 research areas (Table 1). Among these, the top five categories include Food Science Technology (2,886 papers, $100 \%$ of 2,886 papers), Chemistry Applied (1051, 36.417\%), Nutrition Dietetics (822, 28.482\%), Agriculture Multidisciplinary (202, 6.999\%) and Toxicology $(96,3.326 \%)$. The top five research areas include Food Science Technology (2,886 papers, $100 \%$ of 2,886 papers), Chemistry (1066, 36.937\%), Nutrition Dietetics (822, 28.482\%), Agriculture $(318,11.019 \%)$ and Toxicology $(96,3.326 \%)$. Journals or papers may be classified in two or more categories in the WoS, shows the multidisciplinary character of this research field (Elango \& Ho, 2017, 2018). Documents are mapped to one or several research areas in WoS. Areas are assigned to publications and then mapped to each document (paper) in a publication. Therefore, publications can be mapped to several different areas. This broad database-specific mapping has several limitations but is nevertheless widely used in bibliometric assessments. In WoS, publications are also mapped to WoS categories which are more detailed than areas (Stopar et al., 2021).

Table 1. WoS categories and research areas for Food Science and Technology category during 2011-2021.

\begin{tabular}{|c|c|c|c|c|c|c|}
\hline \multirow{2}{*}{ Rank } & \multicolumn{3}{|c|}{ WoS categories } & \multicolumn{3}{|c|}{ Research areas } \\
\hline & Categories & No. papers & $\%$ Total papers & Areas & No. papers & $\%$ Total papers \\
\hline 1 & Food Science Technology & 2886 & 100 & Food Science Technology & 2886 & 100 \\
\hline 2 & Chemistry Applied & 1051 & 36.417 & Chemistry & 1066 & 36.937 \\
\hline 3 & Nutrition Dietetics & 822 & 28.482 & Nutrition Dietetics & 822 & 28.482 \\
\hline 4 & Agriculture Multidisciplinary & 202 & 6.999 & Agriculture & 318 & 11.019 \\
\hline 5 & Toxicology & 96 & 3.326 & Toxicology & 96 & 3.326 \\
\hline 6 & Engineering Chemical & 94 & 3.257 & Engineering & 95 & 3.292 \\
\hline 7 & $\begin{array}{l}\text { Biochemistry Molecular } \\
\text { Biology }\end{array}$ & 90 & 3.119 & Biochemistry Molecular Biology & 90 & 3.119 \\
\hline 8 & Microbiology & 62 & 2.148 & Microbiology & 62 & 2.148 \\
\hline 9 & $\begin{array}{l}\text { Agriculture Dairy Animal } \\
\text { Science }\end{array}$ & 57 & 1.975 & $\begin{array}{l}\text { Biotechnology Applied } \\
\text { Microbiology }\end{array}$ & 57 & 1.975 \\
\hline 10 & $\begin{array}{l}\text { Biotechnology Applied } \\
\text { Microbiology }\end{array}$ & 57 & 1.975 & Pharmacology Pharmacy & 52 & 1.802 \\
\hline 11 & Agronomy & 38 & 1.317 & Business Economics & 16 & 0.554 \\
\hline 12 & Chemistry Medicinal & 37 & 1.282 & Spectroscopy & 14 & 0.485 \\
\hline 13 & Horticulture & 35 & 1.213 & Mycology & 7 & 0.243 \\
\hline 14 & Agricultural Economics Policy & 19 & 0.658 & Entomology & 5 & 0.173 \\
\hline 15 & Economics & 16 & 0.554 & Behavioral Sciences & 4 & 0.139 \\
\hline 16 & Chemistry Analytical & 15 & 0.52 & Neurosciences Neurology & 4 & 0.139 \\
\hline 17 & Pharmacology Pharmacy & 15 & 0.52 & Physiology & 4 & 0.139 \\
\hline 18 & Spectroscopy & 14 & 0.485 & Immunology & 2 & 0.069 \\
\hline 19 & Mycology & 7 & 0.243 & Environmental Sciences Ecology & 1 & 0.035 \\
\hline 20 & Entomology & 5 & 0.173 & Plant Sciences & 1 & 0.035 \\
\hline 21 & Behavioral Sciences & 4 & 0.139 & $\begin{array}{l}\text { Public Environmental } \\
\text { Occupational Health }\end{array}$ & 1 & 0.035 \\
\hline
\end{tabular}




\subsection{Core journals}

Based on JCR 2020 data (published in 2021), there are 144 journals of the WoS categories for Meteorology and Atmospheric Science. All the 2,886 publications were published in 106 journals and two book series which including Annual Review of Food Science and Technology (31) and Annals of the New York Academy of Sciences (1). The top 20 core journals were displayed in the Table 2 with total articles each more than 16 top papers, Journal impact factor as IF 2020 and IF 5 year, rank and Quartile in Food Science and Technology category.

The top 5 journals, top 10 journals, top 15 journals and top 20 journals published about $47.817 \%, 63.202 \%, 72.453 \%$ and $79.487 \%$ of the total top papers, respectively. The top five Journals are Food Chemistry (556, 19.265\%), Food Hydrocolloids (272, 9.425\%), Trends in Food Science Technology (226, 7.831\%), Critical Reviews in Food Science and Nutrition (166, 5.752\%) and Journal of Agricultural and Food Chemistry (160, 5.544\%), each published more than 160 papers. Based on results of Table 2, among top 20 journals, sixteen journals were in Quartile 1, four journals were in Quartile 2 category. White-Gibson et al. (2019) have also demonstrated the importance of publishing articles in the English language in a high IF journals. Citation analysis is not a measurement of scientific quality, but it is reflective of the importance.
According to the publication data in the citation of 106 journals, there were 57 journals meet the thresholds of 5 publications, and were connected to each other. The network of citation in the field of Food Science and Technology category based on WoS was shown nine clusters with different colors in Figure 2, the size of circles reflects a total number of journal publication records. The nine cluster colors from one to nine are red, green, blue, yellow, violet, light blue, orange, brown and pink. Journals in the same cluster usually suggested that they published the similar content papers and had close relations with each other.

\subsection{Authors co-authorship analysis}

In general, internationally collaborative articles had the highest visibility and scientific impact, followed by inter-institutional collaborative articles, single-country articles and single-author articles, respectively (Wambu \& Ho, 2016). According to the published data analysis results, a total of 10,698 authors have 2,886 publications, and among these, 188 authors met the thresholds of five publications, but only 71 authors were connected with each other. The network of authorship in the field of Food Science and Technology category based on WoS represented in Figure 3, the size of circles reflects a total number of records. Authors in the same cluster usually suggested that

Table 2. Top 20 core Journals on Food Science and Technology category research indexed in the WoS.

\begin{tabular}{|c|c|c|c|c|c|c|c|}
\hline Rank & Journal & TP & Ratio & IF 2020 & IF 5year & $\mathrm{QC}$ & QR \\
\hline 1 & Food Chemistry & 556 & 19.265 & 7.514 & 7.516 & Q1 & 7 \\
\hline 2 & Food Hydrocolloids & 272 & 9.425 & 9.147 & 9.169 & Q1 & 5 \\
\hline 3 & $\begin{array}{l}\text { Trends in Food Science } \\
\text { Technology }\end{array}$ & 226 & 7.831 & 12.563 & 14.466 & Q1 & 3 \\
\hline 4 & $\begin{array}{l}\text { Critical Reviews in Food } \\
\text { Science and Nutrition }\end{array}$ & 166 & 5.752 & 11.176 & 11.193 & Q1 & 4 \\
\hline 5 & $\begin{array}{l}\text { Journal of Agricultural and } \\
\text { Food Chemistry }\end{array}$ & 160 & 5.544 & 5.279 & 5.269 & Q1 & 24 \\
\hline 6 & Food Research International & 136 & 4.712 & 6.475 & 6.508 & Q1 & 9 \\
\hline 7 & $\begin{array}{l}\text { Comprehensive Reviews in } \\
\text { Food Science and Food Safety }\end{array}$ & 91 & 3.153 & 12.811 & 15.365 & Q1 & 2 \\
\hline 8 & Journal of Food Engineering & 81 & 2.807 & 5.354 & 5.144 & Q1 & 23 \\
\hline 9 & Food Control & 70 & 2.426 & 5.548 & 5.498 & Q1 & 19 \\
\hline 10 & $\begin{array}{l}\text { LWT Food Science and } \\
\text { Technology }\end{array}$ & 66 & 2.287 & 4.952 & 5.383 & Q1 & 29 \\
\hline 11 & Journal of Dairy Science & 57 & 1.975 & 4.034 & 4.354 & Q2 & 40 \\
\hline 12 & $\begin{array}{l}\text { Molecular Nutrition Food } \\
\text { Research }\end{array}$ & 55 & 1.906 & 5.914 & 6.409 & Q1 & 16 \\
\hline 13 & Foods & 53 & 1.836 & 4.35 & 4.957 & Q2 & 37 \\
\hline 14 & Food Function & 51 & 1.767 & 5.396 & 5.534 & Q1 & 22 \\
\hline 15 & Journal of Functional Foods & 51 & 1.767 & 4.451 & 4.907 & Q1 & 35 \\
\hline 16 & Meat Science & 47 & 1.629 & 5.209 & 5.305 & Q1 & 26 \\
\hline 17 & $\begin{array}{l}\text { Food and Chemical } \\
\text { Toxicology }\end{array}$ & 43 & 1.49 & 6.023 & 5.844 & Q1 & 14 \\
\hline 18 & EFSA Journal & 39 & 1.351 & 3.336 & 3.268 & Q2 & 53 \\
\hline 19 & Toxins & 38 & 1.317 & 4.546 & 4.8 & Q1 & 32 \\
\hline 20 & $\begin{array}{l}\text { Journal of the Science of Food } \\
\text { and Agriculture }\end{array}$ & 36 & 1.247 & 3.638 & 3.802 & Q2 & 47 \\
\hline
\end{tabular}

Note: TP: Total publications; Ratio: Ratio of 2,886(\%); IF 2020: journal impact factor in 2020; IF5 year: journal impact factor of 5 years; QC: Quartile in Category; QR: Quartile rank of 144 journals in Food Science and Technology category. 


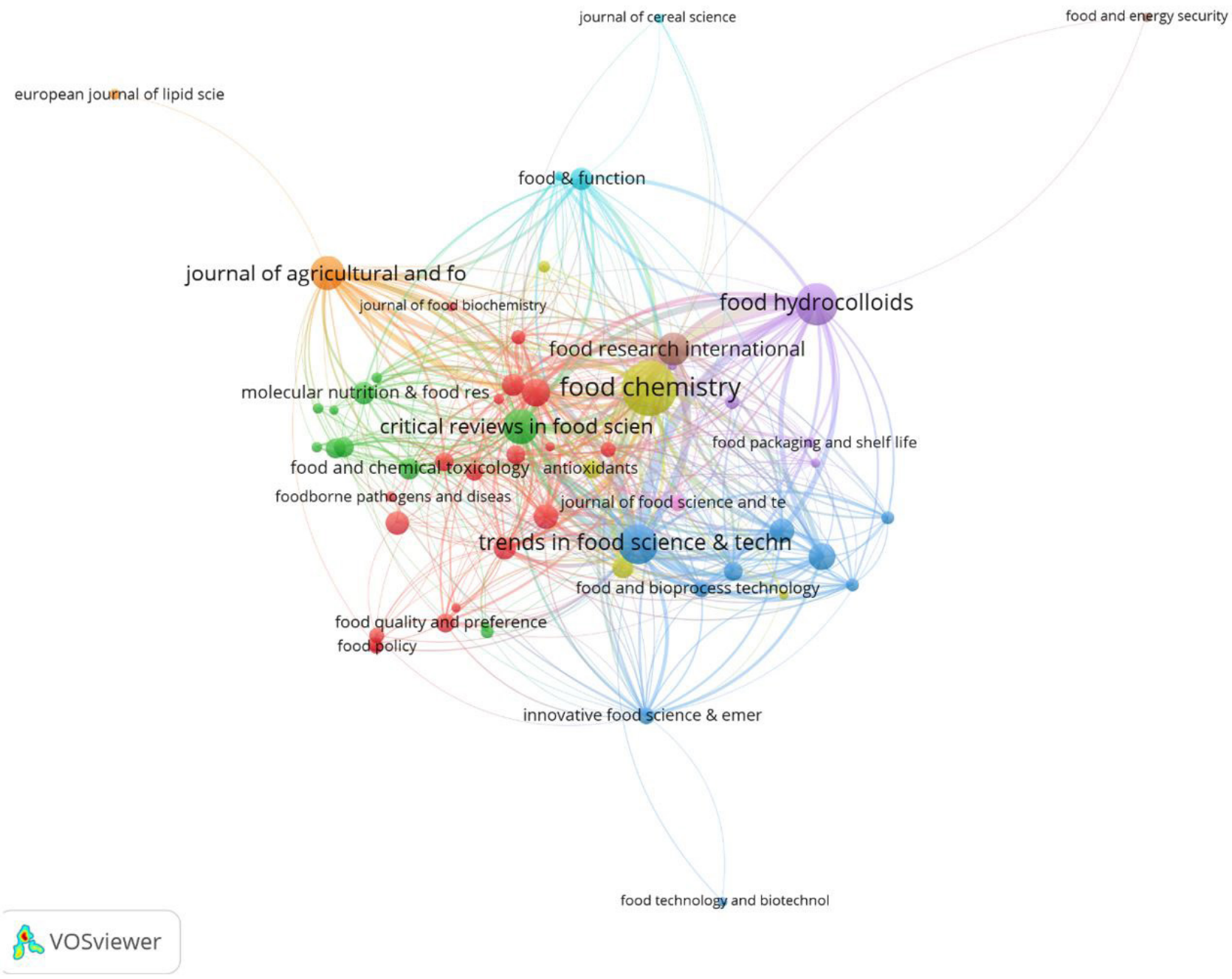

Figure 2. Network visualization maps of citation journals in the field of Food Science and Technology category based on WoS with 57 nodes and 9 clusters.

they studied in a similar field or worked at same institute or had close cooperation with each other.

The detail of author information published articles in the field of Food Science and Technology category from 2011 to 2021 along with citation, average citations, organization-enhenced and countries is provided in Table 3. According to our analysis, the top 14 authors published more than 15 papers. The top five authors were Mcclements, David Julian, Sun, Da-Wen, Barba, Francisco J., Lorenzo, Jose M. and Zhang, Min, each published more than 15 papers. The top five authors with the higher average citations per paper were Ferreira, Isabel C. F. R., Mcclements, David Julian, Granato, Daniel, Sun, Da-Wen and Barba, Francisco J., each paper cited more than 112 times.

\subsection{Countries/regions co-authorship analysis}

There were 115 countries or regions that contributed 2,886 papers in the field of Food Science and Technology category from January, 2011 to June, 2021. Table 4 represent the list of the top 20 countries or regions that published more than
56 papers, and also shows the cluster, total link strength, citations and average citations. Among the top 20 countries, Peoples R China, USA, Spain, Italy, Brazil and India were the major article contributors. In case of average citations, Netherlands, Germany, England, Belgium and Canada showed the higher citations per paper more than 164 times.

We developed the co-authorship network map using VOSviewer (Figure 4). There are 66 countries or regions that met the requirement threshold as five. The size of circles in Figure 4 reflects a total number of records and the distance between the countries indicate the strength of relationships. The VOSviewer divided these 66 circles into six clusters. The different colors group represent the different clusters formed by sets of countries. Distance between the countries indicates the strength of relationships.

According to Figure 4, the first cluster (red color) consisted of twenty-one countries or regions including Malaysia, India, South Korea, Australia, Peoples R China, Saudi Arabia, Japan, Thailand, Austria, Taiwan, Pakistan, Singapore, South Africa, Egypt, Bangladesh, Indonesia, Nigeria, Vietnam, Ghana, U Arab 


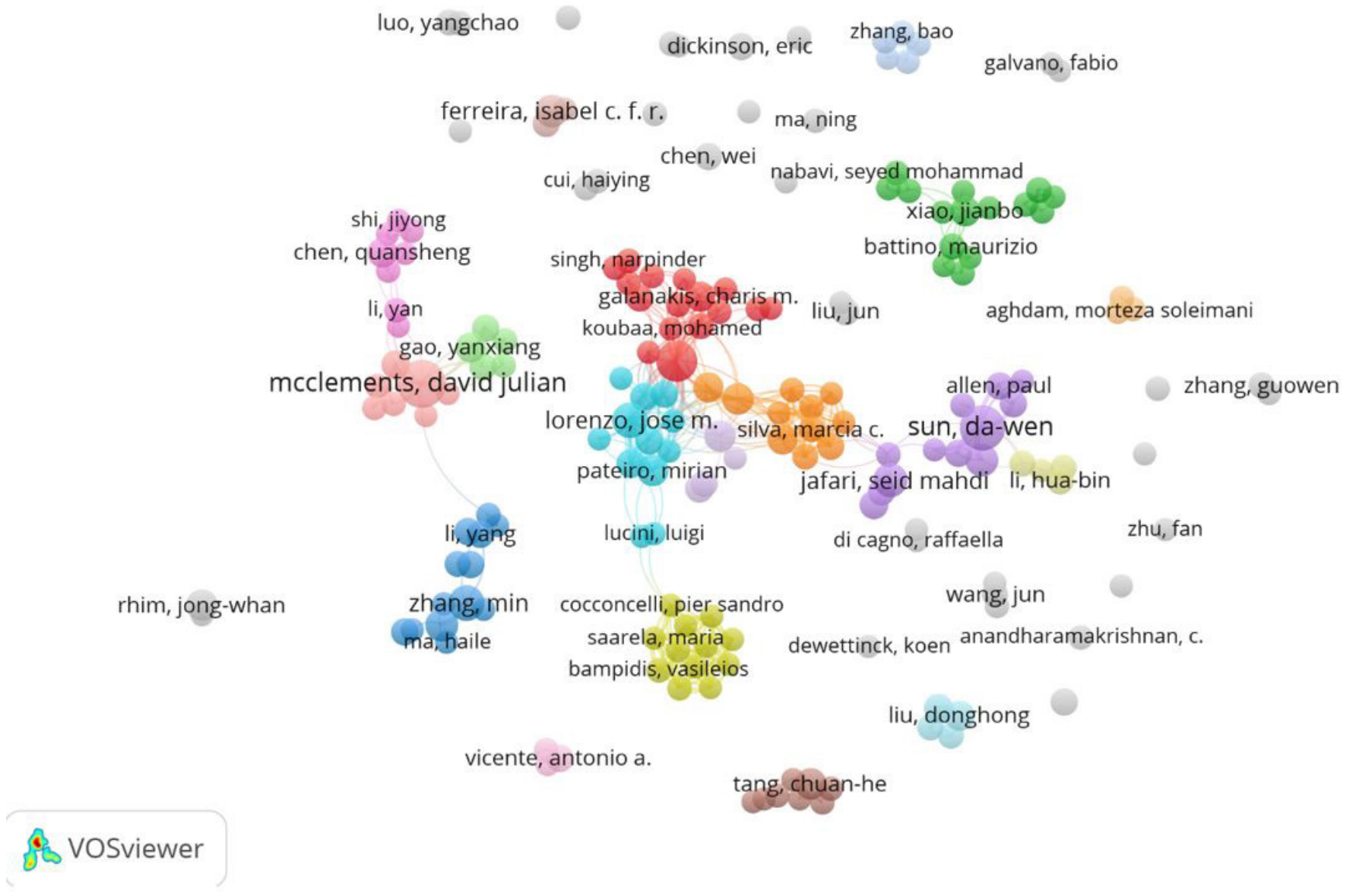

Figure 3. Network visualization map of top authors with more than five papers in Food Science and Technology category from 2011 to 2021. Cooperation based on co-authorship between authors. Network visualization map of authors with minimum productivity of five publications in the studied field and exist within a collaborative research group.

Emirates, Bulgaria. The second cluster (green color) consisted of thirteen countries or regions including Portugal, Turkey, Poland, Greece, Croatia, Norway, Romania, Serbia, Czech Republic, Slovenia, Cyprus, Lithuania, Russia. The third cluster (blue color) consisted of twelve countries including Netherlands, Germany, England, Ireland, New Zealand, Denmark, Switzerland, Sweden, Finland, Scotland, Luxembourg, Wales. The fourth cluster (yellow color) consisted of eleven countries and regions including USA, Spain, Italy, Mexico, Argentina, Israel, Colombia, Chile, Kenya, Ecuador, Philippines. The fifth cluster (violet) consisted of seven countries and regions including Belgium, Canada, France, Tunisia, North Ireland, Algeria, Lebanon. The sixth cluster (shallow blue) consisted of two countries and regions both Brazil and Iran. More cooperation could bring more advanced achievements in scientific research. Nowadays, increasing concept of international exchanges have promoted academic communications (Tang et al., 2018).

\subsection{Organizations co-authorship analysis}

According to the publication data, it was revealed that a total of 2,666 organizations have 2,886 publications. Organization co-authorship analysis reflects the degree of communication between institutions as well as the influential institutions in this field (Reyes-Gonzalez et al., 2016). Table 5 represents the top fifteen organizations and institutions ranked by the number of total publications (more than 32 papers), the total link strength, citations, average citations and country. 
Table 3. The top fourteen most prolific authors published papers in the field Food Science and Technology category from 2011 to 2021.

\begin{tabular}{ccccc}
\hline Rank & Author & Papers & Citations & Average citations \\
\hline $\mathbf{1}$ & Mcclements, David Julian & 65 & 8934 & 137.45 \\
$\mathbf{2}$ & Sun, Da-Wen & 52 & 6430 & 123.65 \\
$\mathbf{3}$ & Barba, Francisco J. & 40 & 4483 & 112.08 \\
$\mathbf{4}$ & Lorenzo, Jose M. & 24 & 1592 & 66.33 \\
$\mathbf{5}$ & Zhang, Min & 23 & 1867 & 81.17 \\
$\mathbf{6}$ & Jafari, Seid Mahdi & 21 & 1827 & 87.00 \\
$\mathbf{7}$ & Ferreira, Isabel C. F. R. & 18 & 3123 & 173.50 \\
$\mathbf{8}$ & Pu, Hongbin & 18 & 1437 & 79.83 \\
$\mathbf{9}$ & Bhandari, Bhesh & 17 & 1521 & 89.47 \\
$\mathbf{1 0}$ & Granato, Daniel & 15 & 1931 & 128.73 \\
$\mathbf{1 1}$ & Pateiro, Mirian & 15 & 925 & 61.67 \\
$\mathbf{1 2}$ & Rhim, Jong-Whan & 15 & 1201 & 80.07 \\
$\mathbf{1 3}$ & Sant'ana, Anderson S. & 15 & 1170 & 78.00 \\
$\mathbf{1 4}$ & Tang, Chuan-He & 15 & 1405 & 93.67 \\
\hline
\end{tabular}

Table 4. Top 20 countries/regions publishing top papers in the field of Food Science and Technology category from 2011 to 2021.

\begin{tabular}{|c|c|c|c|c|c|c|}
\hline Rank & Countries/Regions & Records & Cluster & Total link strength & Citations & Average citations \\
\hline 1 & Peoples R China & 754 & 1 & 450 & 66491 & 88.18 \\
\hline 2 & USA & 487 & 4 & 589 & 74181 & 152.32 \\
\hline 3 & Spain & 283 & 4 & 463 & 40863 & 144.39 \\
\hline 4 & Italy & 210 & 4 & 305 & 24631 & 117.29 \\
\hline 5 & Brazil & 168 & 6 & 190 & 18196 & 108.31 \\
\hline 6 & India & 168 & 1 & 103 & 23499 & 139.88 \\
\hline 7 & Iran & 167 & 6 & 124 & 16104 & 96.43 \\
\hline 8 & Canada & 150 & 5 & 188 & 24609 & 164.06 \\
\hline 9 & England & 134 & 3 & 264 & 22100 & 164.93 \\
\hline 10 & Australia & 132 & 1 & 181 & 16827 & 127.48 \\
\hline 11 & France & 129 & 5 & 293 & 20007 & 155.09 \\
\hline 12 & Ireland & 128 & 3 & 203 & 17997 & 140.60 \\
\hline 13 & Germany & 108 & 3 & 258 & 18330 & 169.72 \\
\hline 14 & Portugal & 101 & 2 & 169 & 16071 & 159.12 \\
\hline 15 & Netherlands & 90 & 3 & 219 & 15300 & 170.00 \\
\hline 16 & South Korea & 83 & 1 & 54 & 10791 & 130.01 \\
\hline 17 & Belgium & 80 & 5 & 156 & 13149 & 164.36 \\
\hline 18 & Turkey & 75 & 2 & 144 & 10808 & 144.11 \\
\hline 19 & Malaysia & 57 & 1 & 59 & 8337 & 146.26 \\
\hline 20 & Poland & 56 & 2 & 88 & 6080 & 108.57 \\
\hline
\end{tabular}

These top 15 organizations were mainly based in China ( 6 organizations), USA (2 organizations), and Spain, Australia, Brazil, Ireland, Belgium, England and Netherlands, each with one organization. Furthermore, the top six organizations of Jiangnan University, University of Massachusetts, South China University of Technology, Zhejiang University, Jiangsu University and University of Valencia were popular based on contribution of articles more than 45 papers each. Similarly in case of citation, the top five organizations of University of Ghent, University of Massachusetts, Wageningen University, Cornell University and University of Leeds showed the higher average citations more than 125.38 times per paper.

Among the total 2,266 organizations, there were 287 organizations met the minimum thresholds of five, and 277 organizations connected to each other (Figure 5). The VOSviewer software divided these 277 institutes into fifteen clusters with different colors. Within the context of network formation, organizations tend to form bonds with other institutions in the same region. Geographical localization is an important factor for partnership and joint venture. Therefore, there is a heavy presence of intrainstitutional relationships within the scientific network on publications.

\subsection{All keywords co-occurrence analysis}

Using the VOSviewer, the mappings can be made for the author keywords, keyword plus and all keywords. For the author keywords, there were 7,175 keywords, and 490 keywords met 


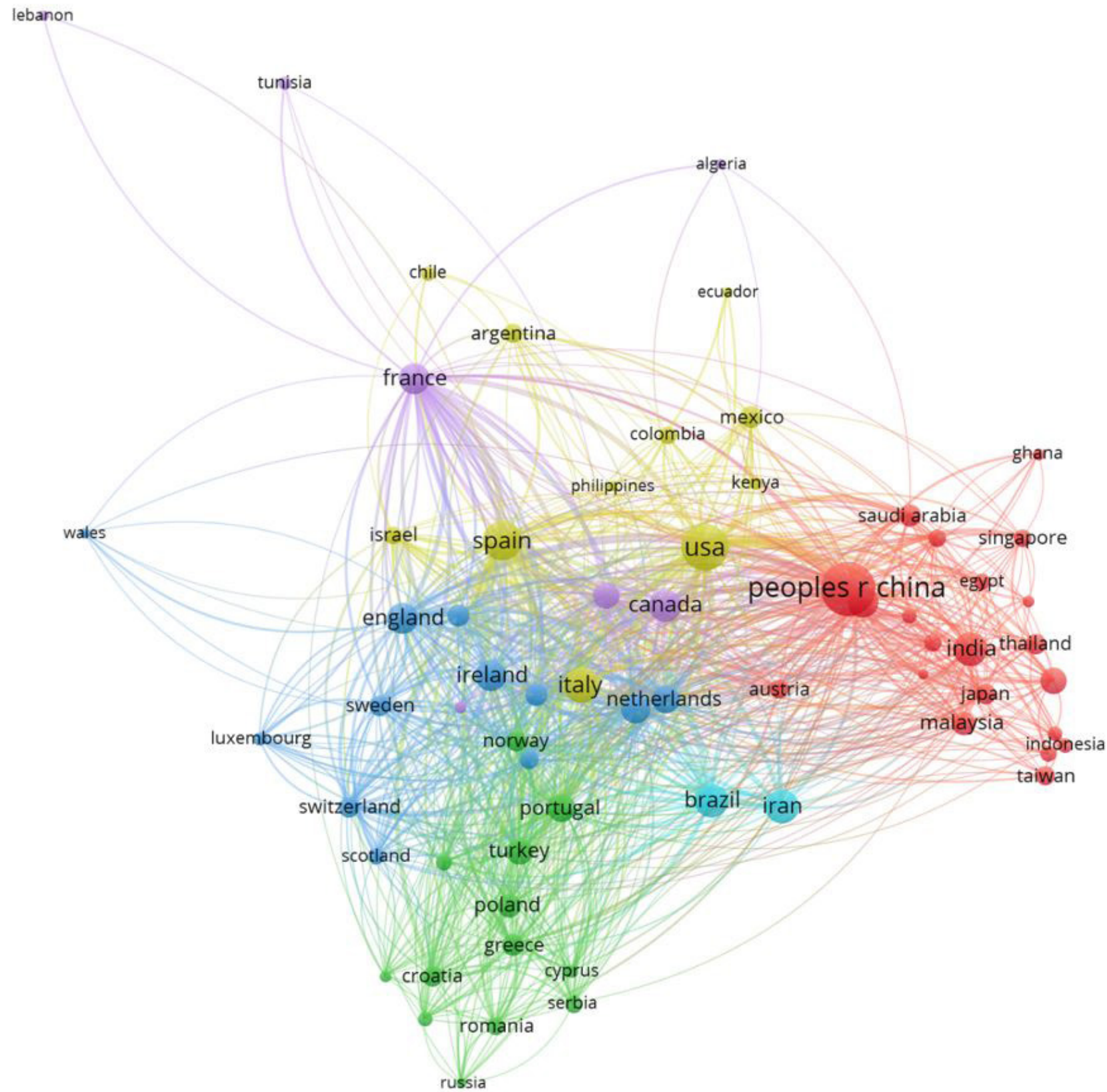

\section{VOSviewer}

Figure 4. The country co-authorship network of Food Science and Technology related top papers from 2011 to 2021 . The country co-authorship network map with 66 nodes and six clusters, the bigger nodes represented the more influential countries in this field. The distance and thickness of links represented the degree of cooperation among countries.

the threshold level of more than five times. The top twenty cooccurrence keywords were antioxidant activity, antioxidant, chitosan, bioavailability, polyphenols, phenolic compounds, food, food safety, curcumin, bioactive compounds, antioxidants, stability, encapsulation, anthocyanins, extraction, health benefits, oxidative stress, bioaccessibility, flavonoids, meat, et al., each keywords occurred more than 39 times. For the keywords plus, there were 9,676 keywords, and 961 keywords met the threshold level of more than five times. The top twenty co-occurrence keywords were in-vitro, antioxidant activity, phenolic-compounds, quality, physicochemical properties, oxidative stress, stability, shelf-life, food, functional-properties, listeria-monocytogenes, chemical-composition, antioxidant, antimicrobial activity, acid, identification, lactic-acid bacteria, antioxidant properties, escherichia-coli, mechanical-properties, et al., each keywords occurred more than 70 times. 
Table 5. Top fifteen organizations publishing papers in the field of Food Science and Technology category from 2011 to 2021.

\begin{tabular}{|c|c|c|c|c|c|c|}
\hline Rank & Organizations & Records & Total link strength & Citations & Average citations & Country \\
\hline 1 & Jiangnan University & 77 & 78 & 7540 & 97.92 & China \\
\hline 2 & $\begin{array}{l}\text { University of } \\
\text { Massachusetts }\end{array}$ & 76 & 89 & 12792 & 168.32 & USA \\
\hline 3 & $\begin{array}{l}\text { South China } \\
\text { University of } \\
\text { Technology }\end{array}$ & 61 & 79 & 4209 & 69.00 & China \\
\hline 4 & Zhejiang University & 48 & 35 & 3383 & 70.48 & China \\
\hline 5 & Jiangsu University & 45 & 27 & 2502 & 55.60 & China \\
\hline 6 & $\begin{array}{l}\text { University of } \\
\text { Valencia }\end{array}$ & 45 & 111 & 5367 & 119.27 & Spain \\
\hline 7 & $\begin{array}{l}\text { China Agricultural } \\
\text { University }\end{array}$ & 43 & 47 & 3923 & 91.23 & China \\
\hline 8 & $\begin{array}{l}\text { University of } \\
\text { Queensland }\end{array}$ & 43 & 33 & 4594 & 106.84 & Australia \\
\hline 9 & $\begin{array}{l}\text { Nanchang } \\
\text { University }\end{array}$ & 40 & 37 & 3632 & 90.80 & China \\
\hline 10 & $\begin{array}{l}\text { Universidade } \\
\text { Estadual de } \\
\text { Campinas }\end{array}$ & 39 & 40 & 4017 & 103.00 & Brazil \\
\hline 11 & $\begin{array}{l}\text { National University } \\
\text { of Ireland }\end{array}$ & 37 & 57 & 4042 & 109.24 & Ireland \\
\hline 12 & Cornell University & 34 & 26 & 4703 & 138.32 & USA \\
\hline 13 & University of Ghent & 33 & 47 & 5781 & 175.18 & Belgium \\
\hline 14 & University of Leeds & 32 & 42 & 4012 & 125.38 & England \\
\hline 15 & $\begin{array}{l}\text { Wageningen } \\
\text { University }\end{array}$ & 32 & 33 & 4646 & 145.19 & Netherland \\
\hline
\end{tabular}

Figure 6 shows the network map that links the all keywords to the entire sample of the articles analyzed. Among all 15,257 keywords, 951 keywords met the threshold level of more than seven times included in the map. There are seven main clusters that represent different viewpoints on Food Science and Technology category research (Figure 6). The top twenty co-occurrence keywords were antioxidant activity, in-vitro, antioxidant, food, quality, stability, physicochemical properties, oxidative stress, polyphenols, phenolic-compounds, chitosan, bioactive compounds, extraction, antimicrobial activity, shelflife, encapsulation, bioavailability, nanoparticles, anthocyanins, functional-properties, listeria-monocytogenes, each keywords occurred more than 88 times.

The same data were then arranged by a period of Food Science and Technology category research as overlay map (Figure 7). Blue colors indicate earlier research topics, whereas, yellow and green colors indicate more recent topics of interest. The blue colored topics do not indicate no longer research work on that topics. It usually indicates that, on average, this topic was intensely investigated earlier and now more attention has shifted towards other topics. Yellow and green circles present those research fronts.

Visualizations conducted on large datasets (big data) offer exploratory information on the current state in a scientific field or discipline as well as indicate possible developments in the future. Here, the top twenty keywords were list and ranked in each cluster based on Figure 6.
The first cluster (Red) is focused on in-vitro antioxidant capacity, and include keywords as in-vitro, antioxidant, oxidative stress, polyphenols, bioavailability, acid, antioxidant capacity, flavonoids, antioxidants, gut microbiota, capacity, inflammation, extracts, metabolism, cancer, nf-kappa-b, extract, health benefits, green tea, inhibition, et al., each keywords occurred more than 32 times.

The second cluster (Green) represents the food stability and physicochemical properties, and include keywords as stability, physicochemical properties, encapsulation, nanoparticles, functional-properties, protein, curcumin, rheological properties, starch, microencapsulation, beta-carotene, impact, microstructure, fabrication, in-water emulsions, oxidative stability, proteins, beta-lactoglobulin, bioaccessibility, pectin, et al., each keywords occurred more than 46 times.

The third cluster (blue) is focused on food quality and food safety, and include keywords as quality, food safety, fruit, performance liquid-chromatography, water, milk, liquidchromatography, toxicity, color, exposure, mass-spectrometry, volatile compounds, mycotoxins, spectroscopy, tandem massspectrometry, food quality, solid-phase extraction, beef, olive oil, quantification, et al., each keywords occurred more than 26 times.

The fourth cluster (yellow) represents variety of the microbiology for different organ food, and keywords include as listeria-monocytogenes, lactic-acid bacteria, escherichia-coli, fruits, growth, fermentation, vegetables, storage, escherichiacoli o157-h7, probiotics, ultrasound, staphylococcus-aureus, 


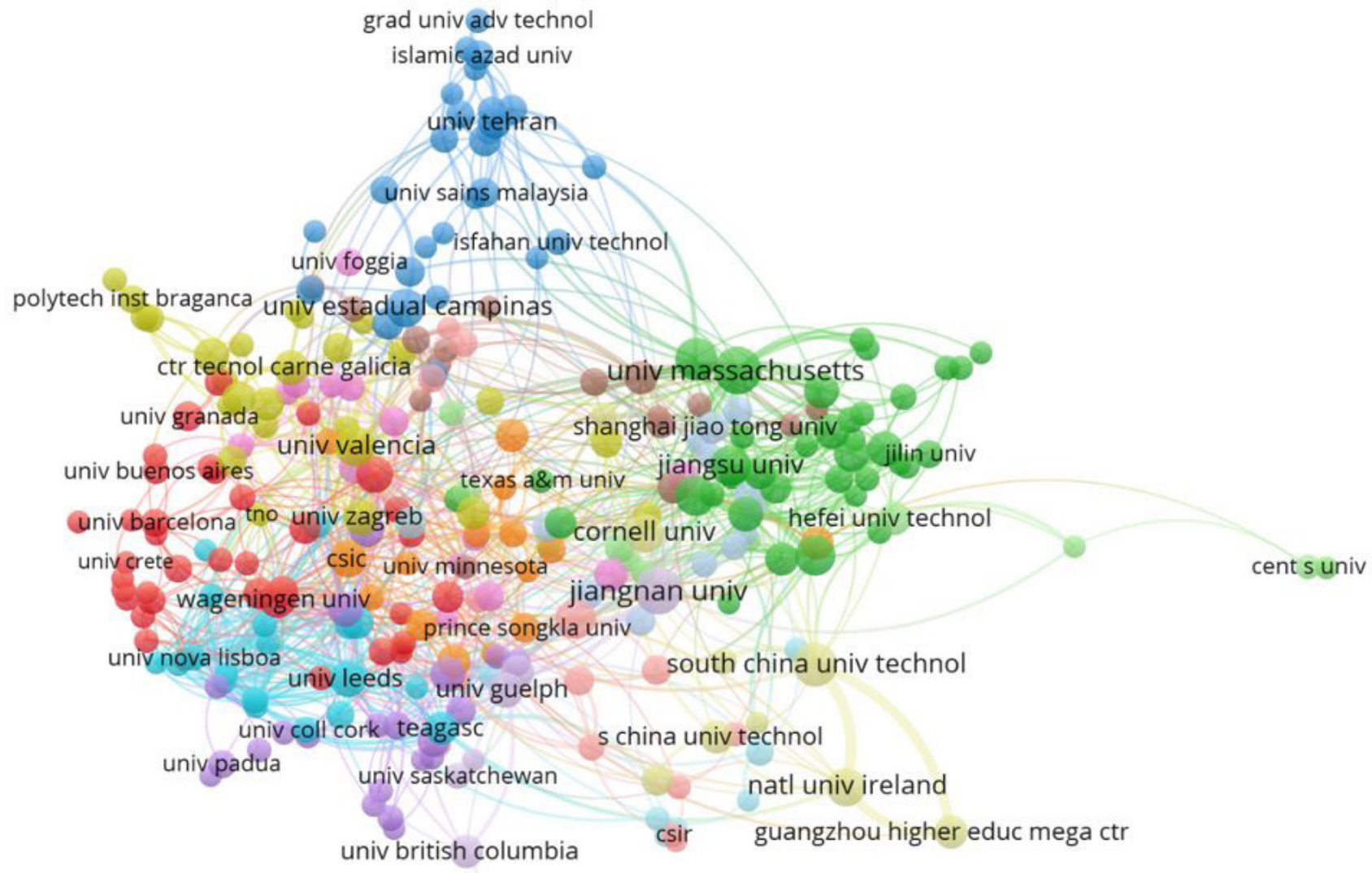

china med univ

\section{VOSviewer}

Figure 5. The organizations co-authorship network of Food Science and Technology related publications from 2011 to 2021. The institutions co-authorship network map with 338 nodes and 9 clusters, the bigger nodes represented the more influential institution in this field. The distance and thickness of links represented the degree of cooperation among organizations.

kinetics, high hydrostatic-pressure, ascorbic-acid, lactic acid bacteria, saccharomyces-cerevisiae, foodborne pathogens, pulsed electric-fields, functional food, et al., each keywords occurred more than 20 times.

The fifth cluster (violet) is focused on antioxidant activity of phenolic-compounds and bioactive compounds, and include keywords as antioxidant activity, phenolic-compounds, bioactive compounds, extraction, anthocyanins, identification, optimization, phenolic compounds, dietary fiber, purification, temperature, polysaccharide, polysaccharides, by-products, functional foods, phenolics, antioxidant activities, bioactive peptides, microwaveassisted extraction, nutraceuticals, et al., each keywords occurred more than 32 times.

The sixth cluster (shallow blue) is focused on antimicrobial activity and shelf-life, keywords are ranked as chitosan, antimicrobial activity, shelf-life, chemical-composition, antioxidant properties, lipid oxidation, antibacterial activity, essential oils, mechanicalproperties, edible films, physical-properties, essential oil, 


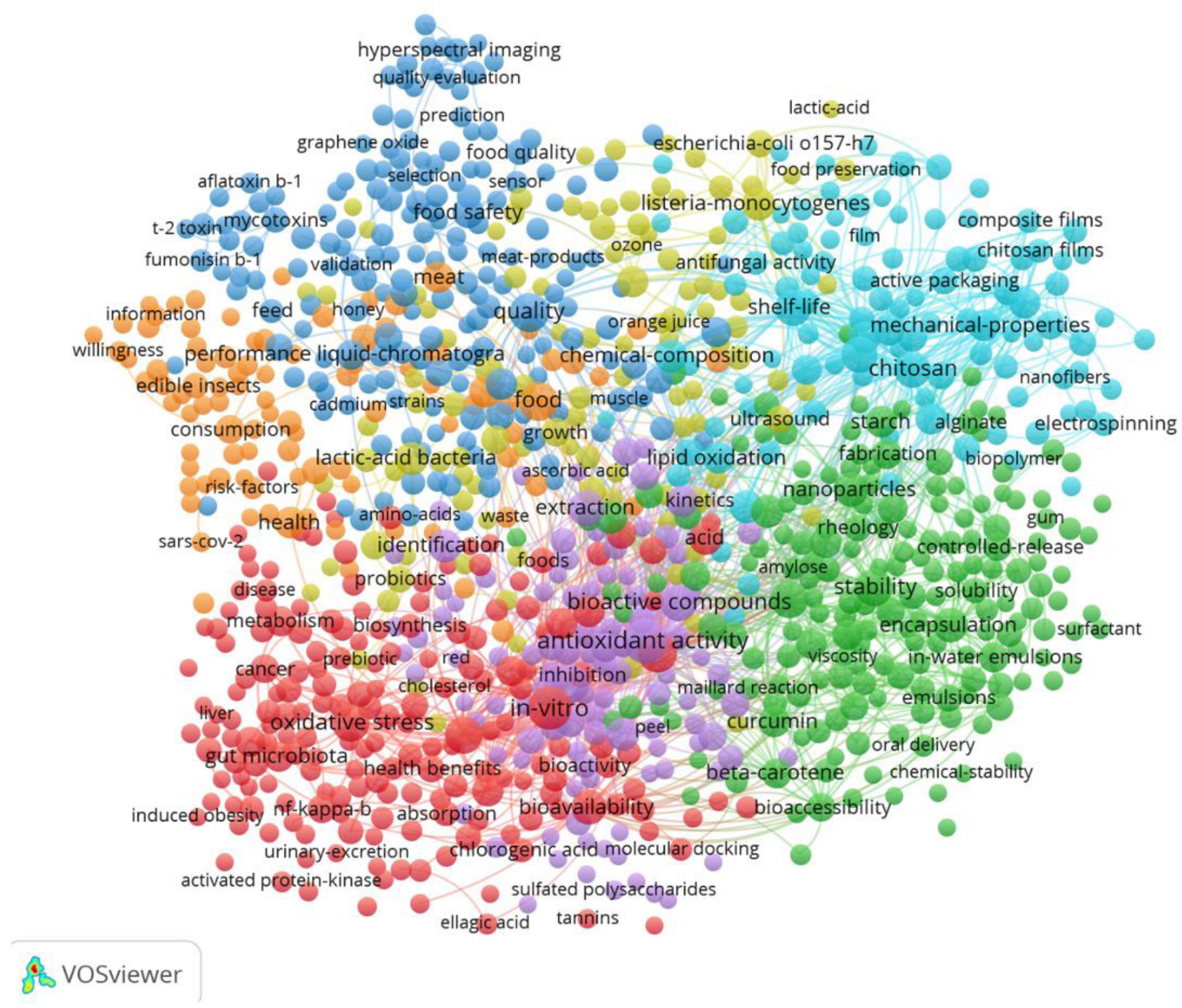

Figure 6. VOSviewer co-occurrence network visualization mapping of most frequent all keywords (minimum of 7 occurrences) in Food Science and Technology. Co-occurrence network of all keywords including author keywords and keywords plus. Of the all 15,257 keywords, there were 951 keywords meet the threshold more than 7 times included in the map. After keywords analysis, there are 7 main clusters that represent 7 different viewpoints on Food Science and Technology.

antibacterial, barrier properties, natural antioxidants, gelatin, release, active packaging, antimicrobial properties, water-vapor permeability, et al., each keywords occurred more than 34 times.

The seventh cluster (orange) is focused on food and health, and keywords are as food, meat, health, products, consumption, nutrition, safety, edible insects, fish, food security, risk assessment, efficacy, nanotechnology, agriculture, model, risk-factors, sustainability, yield, entomophagy, polyunsaturated fatty-acids, et al., each keywords occurred more than 18 times.

\subsection{The most frequently cited articles}

Citation analysis has been employed as a supplementary index to determine the impact of scientific studies, and to identify studies, researchers and the most renowned institutions dealing with the theme. Although a great many articles have been published, a relatively small number of individuals account for a large proportion of the citations within the period. The annual citations of the eight papers showed an increasing trend after year of publication (Figure 8).

The most citations eight papers were written by Minekus et al. (2014), Shahidi \& Ambigaipalan (2015), Bro \& Smilde (2014), Gomez-Guillen et al. (2011), Jeschke et al. (2011), Azmir et al. (2013), Carocho \& Ferreira (2013) and Brewer (2011). Here, the total citations for the most frequently cited each paper were 1922, 1018, 966, 895, 892, 891, 813, 792 times, respectively. The time dependence of a single paper is called its history. In the beginning year (zero year here), generally the articles have lower citation because of same year of publication. From the publication year to 2021, the average citation per year of the 


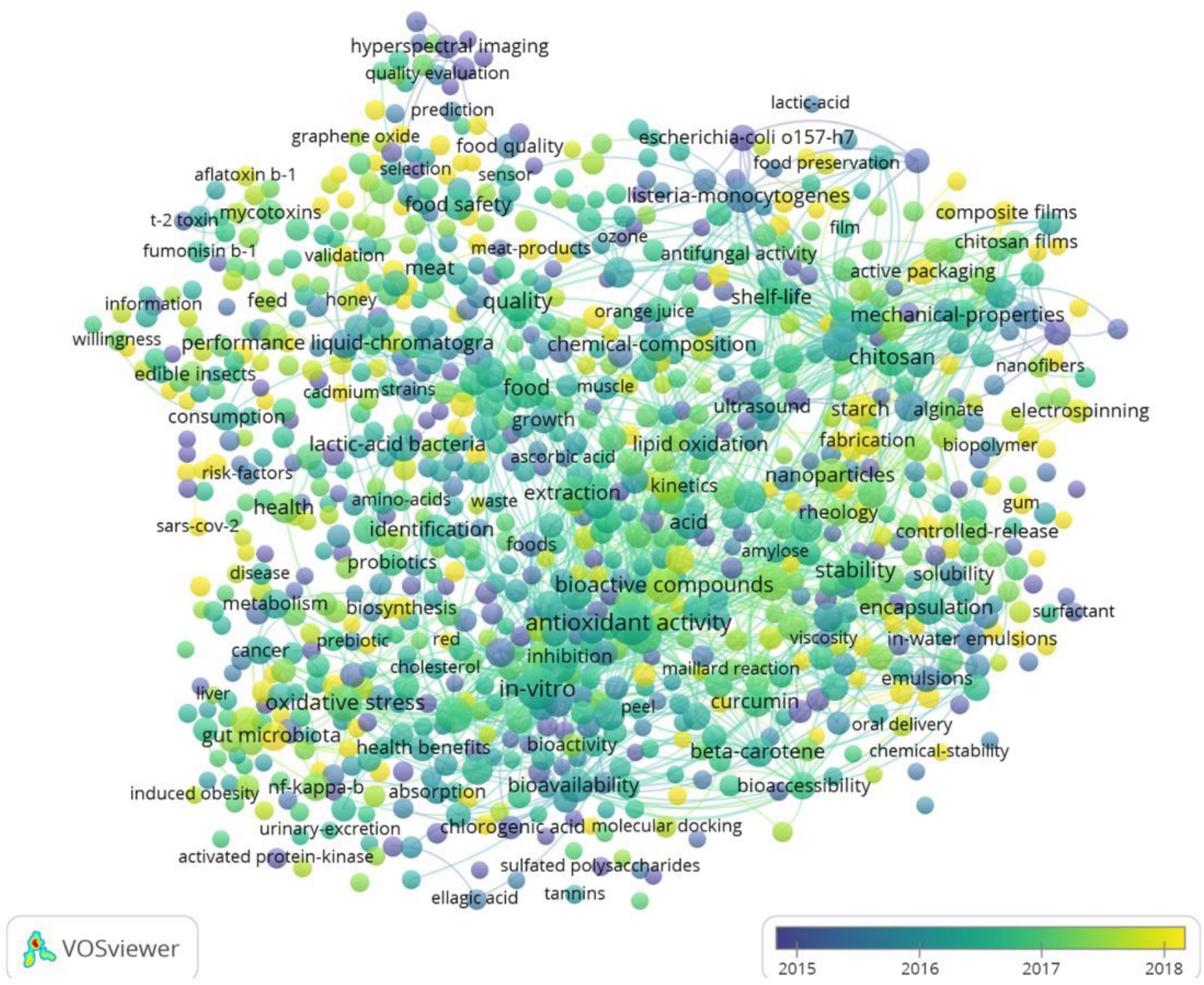

Figure 7. VOSviewer co-occurrence overlay visualization mapping of most frequent all keywords (minimum of 7 occurrences) in Food Science and Technology research from 2011 to 2021.

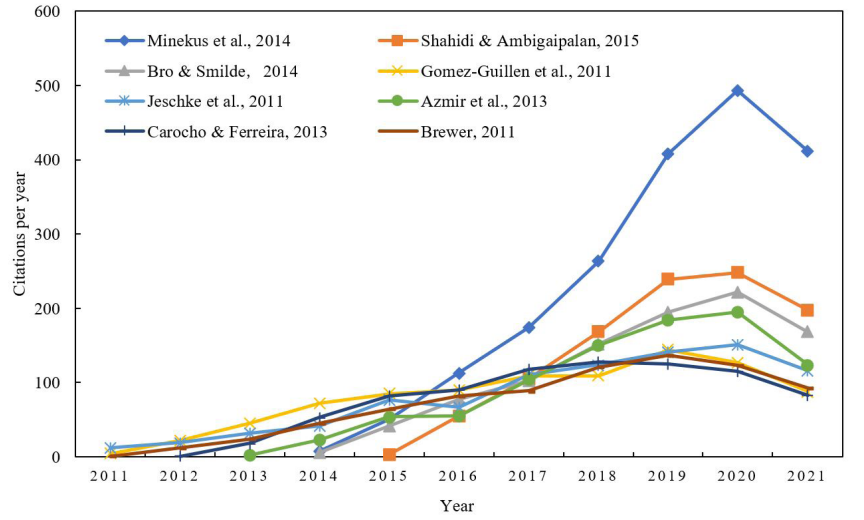

Figure 8. Comparison of the citations per year of the most eight papers from their initial publications to September 9, 2021. most citation eight papers were 240.25, 145.43, 120.75, 81.36, $81.09,99,90.33,72$ times, respectively. From Figure 8 , it can be found that the citation per year of the papers increased till to 2020, but the increase rate was different each year. Among eight papers, the highest average citation per year (240.25-blue color) was observed for article of Minekus et al. (2014) published in Food \& Function (Figure 8).

\section{Conclusions}

This study analyzed 2,886 top papers in the subject category of Food Science and Technology from January 2011 to June 2021, which include 2,882 highly cited papers and 56 hot papers in the field. All papers written in English, were from 10,698 authors, 2,666 organizations and 115 countries/territories, published in 106 journals and two book series in the field. The top five Journals 
are Food Chemistry, Food Hydrocolloids, Trends in Food Science Technology, Critical Reviews in Food Science and Nutrition and Journal of Agricultural and Food Chemistry. Top six countries and regions were Peoples R China, USA, Spain, Italy, Brazil and India. Top six organizations were Jiangnan University, University of Massachusetts, South China University of Technology, Zhejiang University, Jiangsu University and University of Valencia. The top five authors were Mcclements David Julian, Sun Da-Wen, Barba Francisco J., Lorenzo Jose M. and Zhang Min. All keywords were separated seven clusters for different research topic. This work is useful for student identifying graduate schools and researchers selecting journals.

\section{Acknowledgements}

This work was supported by the State Key Special Program of High-yield, High-efficient and Low-cost Technology Research and Model Construction of High Effective Utilization of Annual Light and Temperature, and Accurate Control of Water and Fertilizer in Single and Double Season Rice Mixed Area in North Middle and Lower Reaches of the Yangtze River, grant number 2017YFD0301400; National Key Research and Development Program of China, grant number 2016YFD0300308.

\section{References}

Aleixandre, J. L., Aleixandre-Tudó, J. L., Bolaños-Pizzaro, M., \& Aleixandre-Benavent, R. (2013). Mapping the scientific research on wine and health (2001-2011). Journal of Agricultural and Food Chemistry, 61(49), 11871-11880. http://dx.doi.org/10.1021/jf404394e. PMid:24274031.

Azmir, J., Zaidul, I. S. M., Rahman, M. M., Sharif, K. M., Mohamed, A., Sahena, F., Jahurul, M. H. A., Ghafoor, K., Norulaini, N. A. N., \& Omar, A. K. M. (2013). Techniques for extraction of bioactive compounds from plant materials: a review. Journal of Food Engineering, 117(4), 426-436. http://dx.doi.org/10.1016/j.jfoodeng.2013.01.014.

Bouzembrak, Y., Kluche, M., Gavai, A., \& Marvin, H. J. P. (2019). Internet of Things in food safety: literature review and a bibliometric analysis. Trends in Food Science \& Technology, 94, 54-64. http:// dx.doi.org/10.1016/j.tifs.2019.11.002.

Brewer, M. S. (2011). Natural antioxidants: sources, compounds, mechanisms of action, and potential applications. Comprehensive Reviews in Food Science and Food Safety, 10(4), 221-247. http:// dx.doi.org/10.1111/j.1541-4337.2011.00156.x.

Bro, R., \& Smilde, A. K. (2014). Principal component analysis. Analytical Methods, 6(9), 2812-2831. http://dx.doi.org/10.1039/C3AY41907J.

Carocho, M., \& Ferreira, I. C. F. R. (2013). A review on antioxidants, prooxidants and related controversy: natural and synthetic compounds, screening and analysis methodologies and future perspectives. Food and Chemical Toxicology, 51, 15-25. http://dx.doi.org/10.1016/j. fct.2012.09.021. PMid:23017782.

Cecchini, C., Menesatti, P., Antonucci, F., \& Costa, C. (2020). Trends in research on durum wheat and pasta, a bibliometric mapping approach. Cereal Chemistry, 97(3), 581-588. http://dx.doi.org/10.1002/ cche.10274.

Chuang, K. Y., Wang, M. H., \& Ho, Y. S. (2011). High-impact papers presented in the subject category of water resources in the Essential Science Indicators database of the Institute for Scientific Information. Scientometrics, 87(3), 551-562. http://dx.doi.org/10.1007/s11192011-0365-2.
Clarivate. (2021a). Essential Science Indicators help: about Essential Science Indicators. Retrieved from http://esi.help.clarivate.com/ Content/home.htm

Clarivate. (2021b). InCites Journal Citation Reports. Retrieved from https://jcr.clarivate.com/JCRLandingPageAction.action

Elango, B., \& Ho, Y. S. (2017). A bibliometric analysis of highly cited papers from India in Science Citation Index Expanded. Current Science, 112(8), 1653-1658. http://dx.doi.org/10.18520/cs/v112/ i08/1653-1658.

Elango, B., \& Ho, Y. S. (2018). Top-cited articles in the field of tribology: a bibliometric analysis. Journal of Scientometrics and Information Management, 12(2), 289-307. http://dx.doi.org/10.1080/09737766 .2018 .1529125 .

Florêncio, M. N. D., Gomes, P. C. D., Abud, A. K. D., \& Oliveira, A. M. Jr. (2020). Innovation, research and development on the passion fruit peel flour: bibliometric approach. Food Science and Technology, 40(Suppl. 1), 130-135. http://dx.doi.org/10.1590/fst.05619.

Fu, H. Z., Chuang, K. Y., Wang, M. H., \& Ho, Y. S. (2011). Characteristics of research in China assessed with Essential Science Indicators. Scientometrics, 88(3), 841-862. http://dx.doi.org/10.1007/s11192011-0416-8.

Gomez-Guillen, M. C., Gimenez, B., Lopez-Caballero, M. E., \& Montero, M. P. (2011). Functional and bioactive properties of collagen and gelatin from alternative sources: a review. Food Hydrocolloids, 25(8), 1813-1827. http://dx.doi.org/10.1016/j.foodhyd.2011.02.007.

Guerrero-Bote, V. P., Olmeda-Gómez, C., \& Moya-Anegón, F. (2016). Atlas of scientific institutions in food science (Scopus, 2003-2013). Lebensmittel-Wissenschaft + Technologie, 67, 133-142. http://dx.doi. org/10.1016/j.lwt.2015.11.035.

Hirsch, J. E. (2005). An index to quantify an individual's scientific research output. Proceedings of the National Academy of Sciences of the United States of America, 102(46), 16569-16572. http://dx.doi. org/10.1073/pnas.0507655102. PMid:16275915.

Jeschke, P., Nauen, R., Schindler, M., \& Elbert, A. (2011). Overview of the status and global strategy for neonicotinoids. Journal of Agricultural and Food Chemistry, 59(7), 2897-2908. http://dx.doi. org/10.1021/jf101303g. PMid:20565065.

Kamdem, J. P., Duarte, A. E., Lima, K. R. R., Rocha, J. B. T., Hassan, W., Barros, L. M., Roeder, T., \& Tsopmo, A. (2019). Research trends in food chemistry: a bibliometric review of its 40 years anniversary (1976-2016). Food Chemistry, 294, 448-457. http://dx.doi.org/10.1016/j. foodchem.2019.05.021. PMid:31126486.

Khan, A., Khan, D., \& Akbar, F. (2020). Bibliometric analysis of publications on research into cotton leaf curl disease. Discoveries, 8(2), e109. http://dx.doi.org/10.15190/d.2020.6. PMid:32577497.

Latino, M. E., Menegoli, M., \& Corallo, A. (2020). Food label design - exploring the literature. British Food Journal, 122(3), 766-778. http://dx.doi.org/10.1108/BFJ-06-2019-0452.

Liao, H. C., Tang, M., Li, Z. M., \& Lev, B. (2019). Bibliometric analysis for highly cited papers in operations research and management science from 2008 to 2017 based on Essential Science Indicators. Omega-International Journal of Management Science, 88, 223-236. http://dx.doi.org/10.1016/j.omega.2018.11.005.

Lyu, V. C., Lai, I. K. W., Ting, H. R., \& Zhang, H. F. (2020). Destination food research: a bibliometric citation review (2000-2018). British Food Journal, 122(6), 2045-2057. http://dx.doi.org/10.1108/BFJ09-2019-0677.

Ma, Q., Li, Y. D., \& Zhang, Y. (2020). Informetric analysis of highly cited papers in environmental sciences based on essential science indicators. International Journal of Environmental Research and Public 
Health, 17(11), 3781. http://dx.doi.org/10.3390/ijerph17113781. PMid:32466583.

Maléchaux, A., Le Dréau, Y., Artaud, J., \& Dupuy, N. (2020). Exploring the scientific interest for olive oil origin: a bibliometric study from 1991 to 2018. Foods, 9(5), 556. http://dx.doi.org/10.3390/ foods9050556. PMid:32370096.

Minekus, M., Alminger, M., Alvito, P., Ballance, S., Bohn, T., Bourlieu, C., Carriere, F., Boutrou, R., Corredig, M., Dupont, D., Dufour, C., Egger, L., Golding, M., Karakaya, S., Kirkhus, B., Le Feunteun, S., Lesmes, U., Macierzanka, A., Mackie, A., Marze, S., McClements, D. J., Menard, O., Recio, I., Santos, C. N., Singh, R. P., Vegarud, G. E., Wickham, M. S. J., Weitschies, W., \& Brodkorb, A. (2014). A standardised static in vitro digestion method suitable for food - an international consensus. Food \& Function, 5(6), 1113-1124. http:// dx.doi.org/10.1039/C3FO60702J. PMid:24803111.

Mostafa, M. M. (2020). A knowledge domain visualization review of thirty years of halal food research: themes, trends and knowledge structure. Trends in Food Science \& Technology, 99, 660-677. http:// dx.doi.org/10.1016/j.tifs.2020.03.022.

Reyes-Gonzalez, L., Gonzalez-Brambila, C. N., \& Veloso, F. (2016). Using coauthorship and citation analysis to identify research groups: a new way to assess performance. Scientometrics, 108(3), 1171-1191. http://dx.doi.org/10.1007/s11192-016-2029-8.

Shahidi, F., \& Ambigaipalan, P. (2015). Phenolics and polyphenolics in foods, beverages and spices: antioxidant activity and health effects - a review. Journal of Functional Foods, 18, 820-897. http://dx.doi. org/10.1016/j.jff.2015.06.018.

Shen, C., Wei, M. X., \& Sheng, Y. L. (2021). A bibliometric analysis of food safety governance research from 1999 to 2019. Food Science \& Nutrition, 9(4), 2316-2334. http://dx.doi.org/10.1002/fsn3.2220. PMid:33841848.

Sridhar, K., Inbaraj, B. S., \& Chen, B. H. E. (2021). Recent developments on production, purification and biological activity of marine peptides. Food Research International, 147, 110468. http://dx.doi.org/10.1016/j. foodres.2021.110468. PMid:34399466.

Stopar, K., Mackiewicz-Talarczyk, M., \& Bartol, T. (2021). Cotton fiber in web of science and scopus: mapping and visualization of research topics and publishing patterns. Journal of Natural Fibers, 18(4), 547-558. http://dx.doi.org/10.1080/15440478.2019.1636742.

Sun, J., \& Yuan, B. Z. (2020a). Mapping of the world rice research: a bibliometric analysis of top papers during 2008-2018. Annals of Library and Information Studies, 67(1), 56-66.

Sun, J., \& Yuan, B. Z. (2020b). Bibliometric mapping of top papers in Library and Information Science based on the Essential Science Indicators database. Malaysian Journal of Library and Information Science, 25(2), 61-76.

Sun, J., \& Yuan, B. Z. (2020c). Mapping of top papers in the subject category of water resources based on the Essential Science Indicators. Annals of Library and Information Studies, 67(2), 90-102.

Sun, J., \& Yuan, B. Z. (2021). Trend and research status of Agronomy based on the Essential Science Indicators during 2009-2019. Agronomy Journal, 113(2), 2184-2194. http://dx.doi.org/10.1002/agj2.20628.

Tang, M., Liao, H. C., Wan, Z. J., Herrera-Viedma, E., \& Rosen, M. A. (2018). Ten years of sustainability (2009 to 2018): a bibliometric overview. Sustainability, 10(5), 1655. http://dx.doi.org/10.3390/ su10051655.

Van Eck, N. J., \& Waltman, L. (2010). Software survey: VOSviewer, a computer program for bibliometric mapping. Scientometrics, 84(2), 523-538. http://dx.doi.org/10.1007/s11192-009-0146-3. PMid:20585380.

Wambu, E. W., \& Ho, Y. S. (2016). A bibliometric analysis of drinking water research in Africa. Water S.A., 42(4), 612-620. http://dx.doi. org/10.4314/wsa.v42i4.12.

Wambu, E. W., Fu, H. Z., \& Ho, Y. S. (2017). Characteristics and trends in global tea research: a science citation index expanded-based analysis. International Journal of Food Science \& Technology, 52(3), 644-651. http://dx.doi.org/10.1111/ijfs.13317.

White-Gibson, A., O’Neill, B., Cooper, D., Leonard, M., \& O’Daly, B. (2019). Levels of evidence in pelvic trauma: a bibliometric analysis of the top 50 cited papers. Irish Journal of Medical Science, 188(1), 155159. http://dx.doi.org/10.1007/s11845-018-1818-x. PMid:29752641.

Yang, D. H., Wang, Y., Yu, T., \& Liu, X. Y. (2020). Macro-level collaboration network analysis and visualization with Essential Science Indicators: a case of social sciences. Malaysian Journal of Library and Information Science, 25(1), 121-138.

Yeung, A. W. K., Mocan, A., \& Atanasov, A. G. (2018). Let food be thy medicine and medicine be thy food: a bibliometric analysis of the most cited papers focusing on nutraceuticals and functional foods. Food Chemistry, 269, 455-465. http://dx.doi.org/10.1016/j. foodchem.2018.06.139. PMid:30100460.

Yeung, A. W. K., Tzvetkov, N. T., Zengin, G., Wang, D. D., Xu, S. W., Mitrovic, G., Brncic, M., Dall'Acqua, S., Pirgozliev, V., Kijjoa, A., Georgiev, M. I., \& Atanasov, A. G. (2019). The berries on the top. Journal of Berry Research, 9(1), 125-139. http://dx.doi.org/10.3233/ JBR-180357.

Yuan, B. Z., \& Sun, J. (2019). Bibliometric and mapping of top papers in the subject category of green and sustainable science and technology based on ESI. COLLNET Journal of Scientometrics and Information Management, 13(2), 269-289. http://dx.doi.org/10.1080/09737766 .2020 .1716643 .

Yuan, B. Z., \& Sun, J. (2020a). Bibliometric analysis of research on the maize based on top papers during 2009-2019. COLLNET Journal of Scientometrics and Information Management, 14(1), 75-92. http:// dx.doi.org/10.1080/09737766.2020.1787110.

Yuan, B. Z., \& Sun, J. (2020b). Mapping the scientific research on maize or corn: a bibliometric analysis of top papers during 2008-2018. Maydica, 65(2), M17.

Yuan, B. Z., \& Sun, J. (2021). Research trends and status of wheat (Triticum aestivum L.) based on the Essential Science Indicators during 20102020: a bibliometric analysis. Cereal Research Communications. In press. http://dx.doi.org/10.1007/s42976-021-00200-x.

Zhang, N., Wan, S. S., Wang, P. L., Zhang, P., \& Wu, Q. (2018). A bibliometric analysis of highly cited papers in the field of Economics and Business based on the Essential Science Indicators database. Scientometrics, 116(2), 1039-1053. http://dx.doi.org/10.1007/ s11192-018-2786-7.

Zhong, Q., Wang, L., \& Cui, S. (2021). Urban food systems: a bibliometric review from 1991 to 2020. Foods, 10(3), 662. http://dx.doi.org/10.3390/ foods10030662. PMid:33808855. 